Original Article

\title{
TRENDS OF POISONING AMONG CHILDREN AT KASTURBA HOSPITAL, MANIPAL
}

\author{
Pratik Vijay Tarvadi', Shankar M. Bakkannavar', Manjunath S. ${ }^{3}$, \\ Vikram Palimar ${ }^{4}$, G. Pradeep Kumar ${ }^{5} \&$ Mahabalesh Shetty ${ }^{6}$ \\ ${ }^{1}$ Assistant Professor, Department of Forensic Medicine, KSHEM A, NITTE University, M angalore \\ ${ }^{2}$ Assistant Professor, ${ }^{3}$ Associate Professor, ${ }^{4}$ Additional Professor, ${ }^{5}$ Professor \& HOD, Department of Forensic M edicine, \\ Kasturba M edical College, M anipal University, M anipal. ${ }^{6}$ Professor \& HOD, Department of Forensic M edicine, KSHEM A, \\ NITTE University, M angalore \\ Correspondence: \\ Pratik Vijay Tarvadi \\ Assistant Professor, Department of Forensic M edicine, K.S. Hegde M edical Academy (KSHEM A), NITTE University \\ Nitynanada Nagar, Deralakatte, Mangalore 575018, Karnataka, India \\ M obile : +91 9845306634, Tel. : +91 824 2203030. E-mail : pvtdr@yahoo.com
}

\begin{abstract}
:
Background :Pediatric poisoning is a common medical emergency and also associated with a high morbidity and mortality in children. In developing countries like India, poisoning emergencies are becoming a major cause of mortality in infants and toddlers. Among the various studies conducted on poisoning in our country, the study on poisoning is predominantly on adults and hence this study is taken up to understand the incidence of childhood poisoning cases.
\end{abstract}

Method : A ten year retrospective study from January 1999 to December 2008 was conducted at the Department of Forensic M edicine \& Toxicology, Kasturba M edical College, Manipal, to comprehend the magnitude of childhood poisoning cases at Kasturba Hospital, Manipal.

Results : Insecticide poisoning was the most predominant poisoning followed by venomous bites.

Conclusion : Our study examines the most common poison involved and route of intake among children to identify specific ages at risk and give suggestions so as to reduce the morbidity and mortality.

Keywords: pediatric, poisoning, insecticide

\section{Background :}

Poisoning causes considerable morbidity and mortality worldwide. Irrespective of circumstances of poisoning the victim can be of any age group ranging from an infant to elderly ${ }^{1}$. Although pediatric poisoning most often refers to poisonings occurring among children and adolescents aged less than 18 years, there is an inter-country variation, usually indicating differences between the healthcare systems. ${ }^{2}$ Most exposures Access this article online Quick Response Code

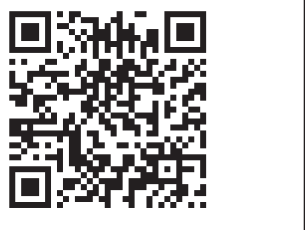
among children are unintentional. $^{3}$ If the harmful agent, for example is stored in a soft drink container, children may fail to recognize the suitability of the liquid and may consume the contents before taste aversion leads to discontinuing the drink. ${ }^{4}$ Intentional poisonings becomes more likely after the age of five. ${ }^{4}$ Children aged 5 to 9 years are less frequently involved in toxic exposures. ${ }^{5}$ Teenagers, on the other hand, are more often involved with poisonings related to substance abuse or suicidal behavior.

The present study attempts to gather epidemiological data regarding poisoning in children in Manipal, so as to formulate recommendations that could probably help to reduce the morbidity and mortality associated with poisoning in these age groups.

\section{Material and Methods:}

The data for the present study is a retrospective research undertaken at the Kasturba Hospital, Manipal, which is a tertiary care teaching hospital, situated in coastal Karnataka, South India, for a period of 10 years (January 
1999 to December 2008).

All the poisoning cases admitted to Kasturba Hospital, $M$ anipal, in the pediatric age group (up to 18 years) ${ }^{7}$ during the study period were included.

The relevant data like age, sex, place of poisoning and outcome was obtained from the Clinical case records from medical records department, Kasturba Hospital, M anipal.

The data obtained was tabulated and analyzed using SPSS (Statistical Package for Social Services) 11 software.

\section{Results:}

A total of 214 cases of poisoning in the pediatric age group were admitted at the Kasturba Hospital, Manipal, during the period of 10 years from January 1999 to December 2008, as depicted in the table no. 1.

Our study showed that, the maximum numbers of pediatric poisoning cases were found to be in the age group of less than 5 years, followed by the age group of 11 to 15 years, 16 to 18 years, and 6 to 10 years respectively, as depicted in the Table No. 2.

In our study, we observed that, the most common substance in the pediatric poisoning cases was insecticide followed by venomous bites, drug over-dosage, kerosene consumption, corrosives etc, as depicted in the Table No. 3.

The route of poisoning reported in our study was by ingestion, 84\% (180) and by injection, 16\% (34). Injection included snake bite and bee stings, as depicted in the Table No. 4.

Our study revealed that, most of the poisoning cases occurred at home, as depicted in the Table No. 5.

Our study revealed that, $95.3 \%$ of cases reported at Manipal hospital had survived while $4.7 \%$ cases had expired, as depicted in the Table No. 6.

\section{Discussion :}

Rise in poisoning is a global phenomenon seen in all age groups amongst all strata of people. This increase in the incidence of poisoning in recent times is due to stress related to academics in children. It is not only the adult population that is affected by poisoning but of late, even children are affected. As health care providers, it is our duty to prevent this rise of morbidity and mortality due to poisoning cases. The present task was undertaken to study the pediatric poisoning so as to reduce the morbidity and mortality.

\section{Age}

Our findings from the pediatric poisoning study revealed that the majority (33\%) of the victims to be in the age group of less than 5 years (preschool age group), followed by 11 to 15 years (29\%). The high incidence of poisoning in the age group of less than 5 years is in accordance with the trends observed nationally 8, 9, 10, 11 and globally. 12, 13, 14, 15, 16, 17 The vulnerability of the preschool age group could be attributed to inquisitiveness and high exploratory activity associated with their developing mobility and hand skills. They also try imitating their parents or grand parents taking medication. Children cannot differentiate between harmless and harmful substances. Incidence of poisoning can also be precipitated by lack of safety measures taken by parents regarding safe storage of medications and pesticides.

Studies conducted at Pakistan, Finland and South Carolina ${ }^{18,} 19,20$ observed high incidence of poisoning amongst adolescent and teen age group.

\section{Poisoning:}

Insecticide compounds were predominantly consumed by children in our study. This is in concurrence with the studies conducted earlier by Palimar et. al. ${ }^{21}$ and Vaswani et. al. ${ }^{9}$, however other studies ${ }^{8,22,23,11,24,16,17}$ revealed that kerosene was the most common poison. The reason for high incidence of insecticide consumption in our study may be attributed to its easy availability in agricultural households. It also reflects the lack of safety measures adopted by the parents in handling these hazardous substances. The high incidence of kerosene poisoning in several other studies were linked to its usage in most of the households as an alternative fuel for cooking and 
Illumination. Studies conducted in Pakistan ${ }^{18}$, Finland ${ }^{19}$ and South Carolina ${ }^{20}$ revealed that habit forming drugs and alcohol showed high prevalence in the teen age group which could be attributed to their adolescent age, academic stress, peer pressure and inappropriate group of friends, thereby increasing their vulnerability for poisoning.

\section{Route of poison :}

Our findings revealed, ingestion to be the major route of poisoning which may be attributed to its convenience and easy availability of orally consumable poisons, a feature observed, which is not only a national phenomenon ${ }^{10}$ but also a global one. ${ }^{25,20}$

\section{Place of Poisoning:}

Eighty percent of pediatric poisoning incidents took place in the victims own home both in accidental and suicidal events. High suicidal incidence at home can be attributed to the preference of the victims for a confined home environment. Similar findings were observed in previous studies conducted at national ${ }^{10}$ and international level. ${ }^{20,25}$

\section{Outcome:}

The mortality rate in our study of pediatric poisoning was $5 \%$, where as the mortality rate ranged from $0.1 \%$ to $16 \%$ in various national ${ }^{8,9,21}$ and international ${ }^{19,12,14,24}$ studies. No deaths were reported in the studies conducted at Pakistan ${ }^{17}$ and United Arab Emirates. ${ }^{2}$

\section{Conclusion :}

Thirty-three percent of pediatric poisoning cases were in the age group of less than 5 years.

Ingestion constituted the major route of entry and was seen in $84 \%$ of the cases.

Insecticide poison was the most common type of poison that was observed in $40 \%$ of the cases.

Poisoning most commonly occurred inside the house (80\%) The survival rate was $95 \%$.

Following measures are suggested to decrease the morbidity and mortality amongst the pediatric population:

I Parental education and awareness

I Child-resistant packaging
I Storage of poisonous substance out of reach of children

I Proper disposal of poisonous substance and their containers after use

I Basic health education duringschooling

I Educating the teen age population regarding handling of stressful situations

\section{Acknowledgements:}

I am extremely thankful to staff of Medical Records Department, Kasturba Hospital, Manipal for their kind help and assistance in collecting data.

Table No. 1: Year wise distribution of cases of poisoning in pediatric age groups $(n=214)$

\begin{tabular}{|l|c|}
\hline Year & Number of cases \\
\hline 1999 & 21 \\
\hline 2000 & 24 \\
\hline 2001 & 16 \\
\hline 2002 & 19 \\
\hline 2003 & 15 \\
\hline 2004 & 15 \\
\hline 2005 & 15 \\
\hline 2006 & 28 \\
\hline 2007 & 32 \\
\hline 2008 & 29 \\
\hline Total & 214 \\
\hline
\end{tabular}

Table No. 2: Age incidence $(n=214)$

\begin{tabular}{|l|c|c|}
\hline Age in years & Number of cases & Percentage \\
\hline$<5$ & 70 & 32.7 \\
\hline $6-10$ & 28 & 13.1 \\
\hline $11-15$ & 63 & 29.4 \\
\hline $16-18$ & 53 & 24.8 \\
\hline Total & 214 & 100.0 \\
\hline
\end{tabular}

Table No. 3: Type of poisoning $(n=214)$

\begin{tabular}{|l|r|c|}
\hline Poison & Total & Percentage \\
\hline Insecticides & 86 & 40.2 \\
\hline Venomous bites & 34 & 15.9 \\
\hline Drug Over-dosage & 27 & 12.6 \\
\hline Kerosene & 20 & 9.3 \\
\hline Corrosives & 18 & 8.4 \\
\hline Rodenticides & 12 & 5.6 \\
\hline Plant Poisons & 11 & 5.1 \\
\hline M etallic Irritants & 3 & 1.4 \\
\hline Herbicides & 2 & 1 \\
\hline Unknown/ unidentified poisons & 1 & 0.5 \\
\hline Total & 214 & 100.0 \\
\hline
\end{tabular}


Table No. 4: Route of poisoning $(n=214)$

\begin{tabular}{|l|c|c|}
\hline Ingestion & Injection & Total \\
\hline 180 & 34 & 214 \\
\hline
\end{tabular}

Table No. 5: Place of poisoning $(n=214)$

\begin{tabular}{|c|c|c|}
\hline \multicolumn{2}{|c|}{ Poisoning } & Total \\
\hline Indoor & Outdoor & \\
\hline 171 & 43 & 214 \\
\hline
\end{tabular}

\section{References:}

1. The Injury Chart Book. Geneva: Department of Injuries and Violence Prevention Non-Communicable Diseases and Mental Health Cluster World Health Organization. 2002

2. Gauvin F, Bailey B, Bratton SL. Hospitalizations for Pediatric Intoxication in Washington State, 1987-1997. Archives of Pediatrics and Adolescent M edicine. 2001; 155: 1105-1110.

3. Hoy J, Day L, Tibballs J, Ozanne-Smith J. Unintentional poisoning hospitalisations among young children in Victoria. Injury Prevention. 1999; 5(1): 31-35

4. Bryant S, Singer J. Management of Toxic Exposure in Children. Emergency M edicine Clinics of North America. 2003; 21: 101-119.

5. Reith DM, Pitt WR, Hockey R. Childhood Poisoning in Queensland: An Analysis of Presentation and Admission Rates. Journal of Paediatrics and Child Health. 2001; 37: 446-450.

6. Cheng TL, Wright JL, Pearson-Fields AS, Brenner RA. The spectrum of Intoxication and Poisonings among Adolescents: Surveillance in an Urban Population. Injury Prevention. 2006; 12: 129-132.

7. https:// www.pediatriccareonline.org/pco/ub/view/Pediatric-DrugLookup/153856/0/ Definition_of_Age_Group_Terminology accessed on $16^{\text {th }}$ M ay 2011.

8. Dutta AK, Seth A, Goyal PK, Aggraval V, Mittal SK, Sharma R, et. al. Poisoning in Children: Indian Scenario. Indian Journal of Pediatrics. 1998; 65: 365-370

9. Vasvani V, Patil VD, Spectrum of Childhood Poisoning: A Belgaum Experience. Journal of Forensic M edicine and Toxicology. 1998; 15(1): 50-52.

10. Gupta SK, Peshin SS, Srivastava A, Kaleekal T. A Study of Childhood Poisoning at National Poison Information Centre, All India Institute of Medical Sciences, New Delhi. Journal of Occupational Health. 2003; 45: 191-196.

11. Deeths T, Breeden J. Poisoning in Children - A Statistical Study of 1,057 Cases. The Journal of Pediatrics. 1971; 78 (2): 299-305.

12. Ossy MJ, Kasilo. A Pattern of Acute Poisoning at Urban Zimbabwe: 10 yrs experience. Human and Experimental Toxicology. 1992; 11(5): 335340.
Table No. 6: Outcome $(n=214)$

\begin{tabular}{|c|c|c|}
\hline \multicolumn{2}{|c|}{ Outcome } & Total \\
\hline Survived & Expired & \\
\hline $204(95.3 \%)$ & $10(4.7 \%)$ & $214(100 \%)$ \\
\hline
\end{tabular}

13. Dawson KP, Harron D, McGrath L, Amirlak I, Yassin A. Accidental Poisoning of Children in the United Arab Emirates. Eastern Mediterranean Health Journal. 1997; 3(1): 38-42.

14. Lucas GN. Acute Drug Poisoning in Children. Sri Lanka Journal of Child Health. 2000; 29: 45-48.

15. M oghadamnia A, Shirvani AK, Esmaeili M R, Bayati Z, Gholitabar ZM . A Report of Childhood Poisoning in Babol. Archives of Iranian M edicine. 2004; 7(4): 297-299.

16. Koushanfar A. A Study of Accidental Children Poisoning. Archives Iranian Medical Journal. 2000; 3: 25-29.

17. Shideh A, Shiva H, Elena L, M ohamad P, M orteza J. Acute Poisoning in Children. Pakistan Journal of M edical Sciences. 2009; 25(1): 51-54.

18. Jan M A, Siddiqui TS, Haq IU, Khan Z. M ushroom Poisoning in Children: Clinical Presentation and Outcome; Journal of Ayub Medical College Abottabad. 2008; 20(2): 99-101

19. Kivisto JE, Arvola T, Parkkari J, Mattila VM. Paediatric Poisonings Treated in One Finnish Main University Hospital Between 2002 and 2006. Acta Paediatrica. 2008; 97: 790-794.

20. Teresa A, Campbell, Collins KA. Paediatric Toxicology Deaths a 10-year Retrospective Study. The American Journal of Forensic M edicine and Pathology. 2001; 22(2): 184-187.

21. Surjit S, Sunit S, Sood NK, Lata K, Walia BNS. Changing Pattern of Childhood Poisoning (1970-1989): Experience of a Large North Indian Hospital. Indian Pediatrics. 1995; 32: 331-336.

22. Sharma U, Saxena S. Accidental Poisoning in Children in Jaipur (Rajasthan). Indian Journal of Pediatrics. 1974; 41(5): 174-178.

23. Sarker AK, Ghosh S, Barik K. A Study of Accidental Poisoning (in Children) in a Rural Medical College Hospital of West Bengal. Indian Journal of Public Health. 1990; 34(3): 159-62.

24. Rashid AKM , Sultana R, Ahasan HAM N, Rasul CH. Seasonal Variation of Childhood Acute Poisoning. Pakistan Journal of Medical Sciences. 2007; 23(3): 443-445.

25. Sharif F, Khan RA, Keenan P. Poisoning in a Pediatric Hospital: Irish Journal of Medical Science. 2003; 172(2): 78-80. 